\title{
Procedure and reliability of conditioned respiratory suppression
}

\author{
S. STEFAN SOLTYSIK, NANCY K. DESS, W. JEFFREY WILSON, \\ JOHN A. MATOCHIK, and STEVE BERG \\ University of California, Los Angeles, California
}

\begin{abstract}
Changes in respiration amplitude, respiration rate, and heart rate in response to a conditioned signal for shock were measured concurrently in kittens and adult cats. The data were analyzed with respect to qualitative and quantitative variability across trials and subjects; correlation among measures; skewness; and kurtosis. Suppression of respiration amplitude was the most reliable response across trials and subjects, with increases in respiration rate second and heart rate by far the least reliable. Correlations between each pair of measures were moderate. Respirationamplitude responses were negatively skewed, but this deviation from normality was moderate and consistent across subjects. The measurement of conditioned respiratory suppression is a viable addition or alternative to the conditioned emotional response procedure in studies of classically conditioned fear.
\end{abstract}

Experimental measures of "fear" (e.g., heart rate, instrumental escape or avoidance behavior, motor reflexes) often suggest that fear conditioning is slow (Harrison \& Buchwald, 1983) or idiosyncratic to the situation, age, species, or prior experience of the subjects (Gibson, 1952; Reynierse, Scavio, \& Ulness, 1970; Soltysik \& Konorski, 1966; Thompson, 1986; Thompson et al., 1987). However, many popular indices of fear may reflect the selection of behavioral coping strategies, prompted by learned fear, rather than the associative learning process per se. Biobehavioral science needs measures of fear that are sensitive, reliable, useful in a variety of subjects, and easy to interpret.

Several recent studies suggest that conditioned respiratory suppression (CRS) is a sensitive, robust, and reliable index of learning (Soltysik, Nicholas, \& Wilson, 1984; Soltysik \& Wolfe, 1980; Soltysik, Wolfe, Nicholas, Wilson, \& Garcia-Sanchez, 1983). Furthermore, respiration requires no pretraining and is not uniquely related to particular motivational systems. Respiration also matures early and does not undergo profound developmental changes, making it ideal for ontogenetic studies. This report describes the CRS procedure, evaluates its reliability, and provides a comparison of CRS with concurrent respiration-rate and heart-rate changes. Data are

Most of the computer programs used in this study were written by W. J. Wilson. The authors would like to express their gratitude to Richard Jackson for his assistance with the experiments and with data processing. This study was supported by Research Training in Mental Retardation Grant HD 07032 from NICHD and by a Biomedical Research Support Grant, UCLA, awarded to N. Dess, and by a UCLA Senate grant awarded to S. Soltysik. N. K. Dess is presently at the Department of Psychology, Occidental College, Los Angeles, CA 90041. W. J. Wilson is presently at the Department of Psychological Sciences, Indiana University-Purdue University at Fort Wayne, Fort Wayne, IN 46805. Address correspondence to S. Soltysik, MRRC, NPI-58258, UCLA, Los Angeles, CA 90024. presented from the conditioned stimulus-unconditioned stimulus (CS-US) interval of individual trials at the asymptotic stage of acquisition in adult cats and in 9-10-weekold kittens. Intrasubject and intersubject variability of the three dependent measures and their intercorrelations are presented and discussed. The CRS is evaluated as an important addition to the battery of measures used in learning, developmental, and neurophysiological studies.

\section{METHOD}

\section{Subjects}

The subjects were 5 adult cats and 5 kittens 2 months old at the start of the experiment. They were selected randomly from a larger pool of subjects for the purpose of comparing three types of data: respiration rate, respiration amplitude, and heart rate. The only criterion for selection was the presence of the three types of data at the onset of the experiment. The subjects were born in the MRRC Kitten Colony at UCLA. All subjects received veterinary care, including weekly inspections and vaccinations against feline distemper and feline rhinotracheitis.

\section{Apparatus}

The apparatus has been described in detail by Wolfe and Soltysik (1981). Briefly, the training stand consisted of a steel frame that supported a canvas harness and treadmill. The stand was located in a large, sound-attenuating box in which several stimuli could be presented. The CSs - a 5-sec 2000-Hz tone and a $5-\mathrm{sec} 10-\mathrm{Hz}$ train of clicks-were presented when scheduled through two doublecone speakers at the rear of the box. Electrodes coated with electrode paste were attached to the base of the tail and at the plantar region of the left foot with Velcro; a $0.3-\mathrm{sec}, 60-\mathrm{Hz}$ electric shock delivered through the electrodes from a shock generator served as the US. Shock intensity was adjusted between 2.0 and $2.75 \mathrm{~mA}$ as necessary to maintain a robust unconditioned flexion response to shock in each animal. Because the plantar electrode $\left(\sim 1 \mathrm{~cm}^{2}\right)$ was several times smaller than the tail electrode $\left(\sim 6 \mathrm{~cm}^{2}\right)$, the intensity of the aversive stimulus (or current density) was much higher under the foot electrode. Still, the intensity was selected such that no disruptive agitation followed the flexion response and the sub- 
jects were calm between trials, returning quickly to the calm state within a few seconds of shock termination.

Respiration was detected via a thermistor placed in front of the naris. Heart rate was obtained from electrodes in the abdominal cavity and on the cranium. The data were taken $10 \mathrm{sec}$ before the trial, during the trial, and $10 \mathrm{sec}$ after the trial. The analog-to-digital conversion and further data reduction were carried out on Apple computers, as described previously (Wolfe \& Soltysik, 1981).

\section{Training}

The subjects were trained with two types of trials: danger signals (DS) followed after 5 sec by a shock; or a danger signal combined after $2 \mathrm{sec}$ with a safety signal, with the signals terminating simultaneously $5 \mathrm{sec}$ after trial onset. Only the data from the DS-shock trials were used in this analysis. The last 16 consecutive reinforced trials in Sessions 10 through 20 were used; nearly asymptotic performance was attained at this stage of training, so the effect of the correction for the slope was negligible (Table 1).

\section{Data Reduction}

For each type of data (respiration amplitude, respiration rate, and heart rate), 100 data points were collected from each trial. The sampling was performed every $250 \mathrm{msec}$, so 40 data points were obtained from the 10-sec pre-DS period, 20 data points fell within the 5-sec DS-shock interval, and 40 data points came from the 10 sec period after the shock. The data from one trial were reduced to a single score by averaging 8 data points between 2.5 and $4.5 \mathrm{sec}$ of the DS-shock interval (see the stippled areas in the figures). This part of the "response" was selected because it reflects maximal development of conditioned response (CR). It is late enough to exclude the initial, or "alpha CR"-type, response, which is presumably attentional or orienting, as well as the data points immediately preceding the shock, when the record may be distorted by sudden movement or vocalizations. Sixteen single trial scores from each subject constitute the basis for the analysis of variability and of comparison and intercorrelations between subjects, trials, and type of data.

\section{Statistical Data Analysis}

The reliability of the three types of data was compared with the standard coefficient of variation (Zar, 1974, p. 34), which expresses sample variability relative to the sample mean: $V=\mathrm{SD} /$ mean or $V=(\mathrm{SD} / \mathrm{mean}) \times 100 \%$. This measure of relative variability allows comparison of the reliability of data expressed in different units. It should be stressed that the initial transformation of our three types of data did not affect their variability. Heart rate and respiration rate were expressed as beats or cycles per minute, as is accepted for these physiological measures. Respiration amplitude was measured from the nasal thermistor in volts, but the magnitude of "response" was dependent on the position of the thermistor. It remained stable within the session, but its absolute values were not comparable across sessions. Each data point of the respiration amplitude was therefore immediately converted to a percentage of the mean of the $\mathbf{4 0}$ pre-DS data points (baseline respiration amplitude). This conversion gives the pre-DS mean a value of 100 and does not change the relative variability of the responses: $V$ for the original raw data and the transformed data is the same.

Skewness and kurtosis of data from the 16 trials were calculated for each subject to assess departure of the distributions from normality. Skewness refers to the symmetry of a distribution. A positively skewed distribution has relatively few observations in a long "tail" representing more positive (or less negative) values; a negatively skewed distribution has relatively few observations in a long tail representing more negative (or less positive) values. Kurtosis refers to how tightly values cluster about the mean. Positive kurtosis, or leptokurtosis, reflects relatively tight clustering about the mean; negative kurtosis, or plarykurtosis, reflects a relatively broad distribution about the mean (see Zar, 1974, for formulae).

Pair-wise correlations among dependent measures were assessed with Pearson's product-moment coefficient of correlation, $r$.

\section{RESULTS}

Data from 16 consecutive excitatory conditioning trials were examined first for general form of response during trials. Respiration amplitude, respiration rate, and heart rate were sampled concurrently at 0.25 -sec intervals; the data were then averaged over trials for each subject (Figures 1, 2, and 3).

Figure 1 reveals the pattern of changes in respiration amplitude over the course of the trial. Respiration amplitude decreased monotonically during the DS-shock period relative to the pre-DS baseline in 9 of 10 subjects; one subject, KT001, showed an early, rapid decrease and recovery before its respiration amplitude became suppressed again in the second half of the 5-sec DS-shock interval. Suppression of respiration amplitude was maximal and sustained over the 2-3-sec preceding shock onset in each animal, except for ACO01, which, although still suppressed, showed some return toward baseline in the late part of the DS-shock interval.

Respiration rate generally increased during the DS-shock interval (see Figure 2). A notable exception was ACOO4; this subject demonstrated a more complex and less dramatic change in rate during the DS than did the other subjects, although it showed typical, simple, profound changes in respiration amplitude during the same trials (see Figure 1). Patterns of change in respirationrate data appear to be less consistent than respirationamplitude patterns. The subjects displayed a multitude of patterns of local changes in rate; some responses were basically monotonic (e.g., AC002, KT002, and KT003), whereas others were biphasic or irregular (e.g., AC003, AC005, and KT001).

A general description of heart-rate patterns (see Figure 3) is even more difficult. Useable heart-rate data were not available for 2 subjects (AC005 and KT001) for each of the 16 trials, although respiration data on the same trials for those cats were perfectly acceptable. The data were lost through a variety of mechanical and movement artifact problems, testimony to the practical disadvantage often involved in collecting heart-rate data in free-moving animals. In the remaining 8 cats, heart rate tended to be depressed in the later part of the DS. However, there was only miniscule depression in 2 subjects (ACO04 and KTO03), and response patterns throughout the trial varied, especially between kittens and adult cats. Heart rate accelerated early after the DS onset, then decelerated, in 3 of the 4 adult cats; none of the 4 kittens showed this pattern of response. This replicates previous studies on the ontogeny of heart-rate aversive conditioning (Nicholas et al., 1983; Soltysik, Wolfe, Garcia-Sanchez, \& Nicholas, 1982) that showed a variety of patterns in adult 

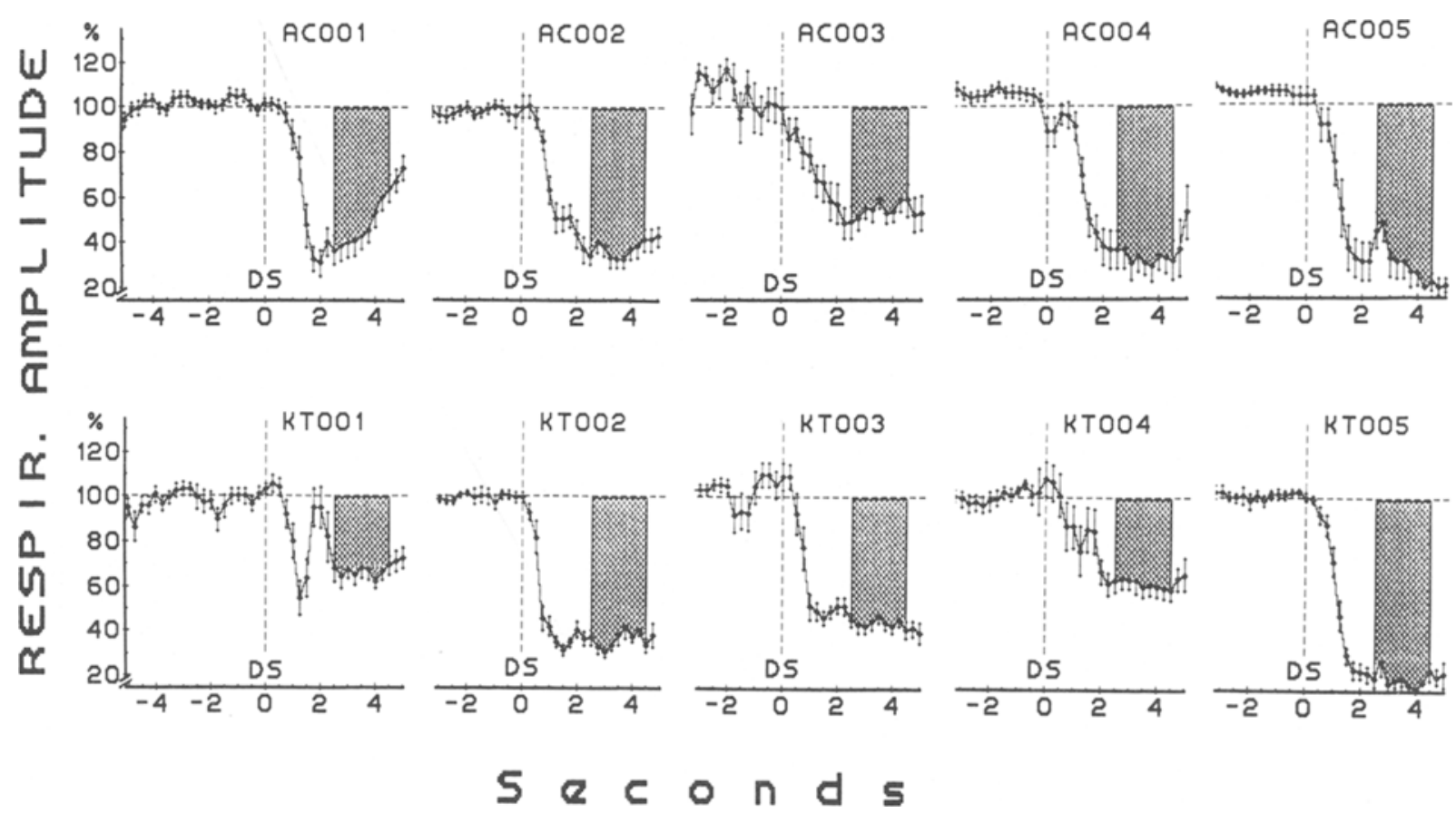

Figure 1. Respiration amplitude as a percent of baseline amplitude for 5 sec preceding DS onset and 5 sec during DS presentation. Graphs are presented for individual adult (upper) and kitten (lower) subjects. Stippling indicates the period from which the late CR measure was calculated.

cats but a consistent deceleration in younger kittens, which remain immobile during the DS-shock interval.

Several statistical analyses confirmed that respirationamplitude responses within and between subjects were more reliable than respiration rate or heart rate. These analyses were based on single scores on each trial for each subject. In concordance with our earlier heart-rate studies (Nicholas et al., 1983; Soltysik et al., 1982), and with the data on respiration rate and heart rate in this paper, there is an indication that the behavior during the $5 \mathrm{sec}$ of the DS-shock period is divided into two phases: an early response in the first $1.5-2.5 \mathrm{sec}$ and a late response in the 2-3 sec before the shock. Cardiac and respiratory measurements in the last $0.5 \mathrm{sec}$ prior to shock onset are sometimes marred by artifacts or sudden movements of the animal; therefore, the optimal period for measuring the late CR is from 2.5 to $4.5 \mathrm{sec}$ after DS onset. The magnitude of the CR during this period is represented by the stippled area in each frame of all figures. The average value of 8 data points from this 2 -sec epoch from each individual trial is used for further statistical examination.

First, a coefficient of variation $[V=(\mathrm{SD} /$ mean $\times$ $100 \%$ ] based on the CR on 16 separate trials was calculated for each subject on each dependent variable. $V$ scores constitute a scale of "nonunits" comparable across different types of data. Sixteen trials were selected from late training sessions (Sessions 10-20) to minimize any contribution of any continued learning to variation among the trials; however, to control for systematic changes in conditioned responding across sessions that potentially differed between the measures, regression analysis was performed for each dependent variable and $V s$ were corrected for the slope of the regression line. The uncorrected and corrected values of $V \mathrm{~s}$ for each subject and the group means of the $V_{\mathrm{s}}$ are reported in Table 1.

The group mean $V s$ reflect intertrial variability averaged over all subjects; by this index, respiration amplitude $(V=26.22 \%)$ was less variable than either respiration rate $(V=43.12 \%)$ or heart rate $(V=267.63 \%)$.

Skewness and kurtosis of CRs across trials were calculated (Zar, 1974) for each subject. This analysis allowed the assessment of the degree and direction of departures of responding from normality within subjects, as well as of the consistency of response distributions within and between age groups. Individual and group mean coefficients are represented in Table 2 . The measures were not significantly or differentially kurtotic. Respiration amplitude was moderately skewed, significantly more so than respiration rate $[t(9)=3.35, p=0.008]$ and heart rate $[t(7)$ $=3.1, p=0.02$ ]. Skewness does not pose a problem for tests of significance when the skew is moderate and when entities (e.g., age groups, trial types, etc.) to be compared are homogeneous with respect to skewness (Kirk, 1968). The negative skew $(-0.72)$ in respiration amplitude was consistent across all subjects (SEM = 0.08 ), and was consistent in sign and degree across age groups (adult cats, -0.69 ; kittens, -0.75 ).

Respiration rate was consistently negatively skewed for kittens (mean $=-0.51$ ), whereas the degree and sign of the skew among adults was variable $($ mean $=0.23)$. There 


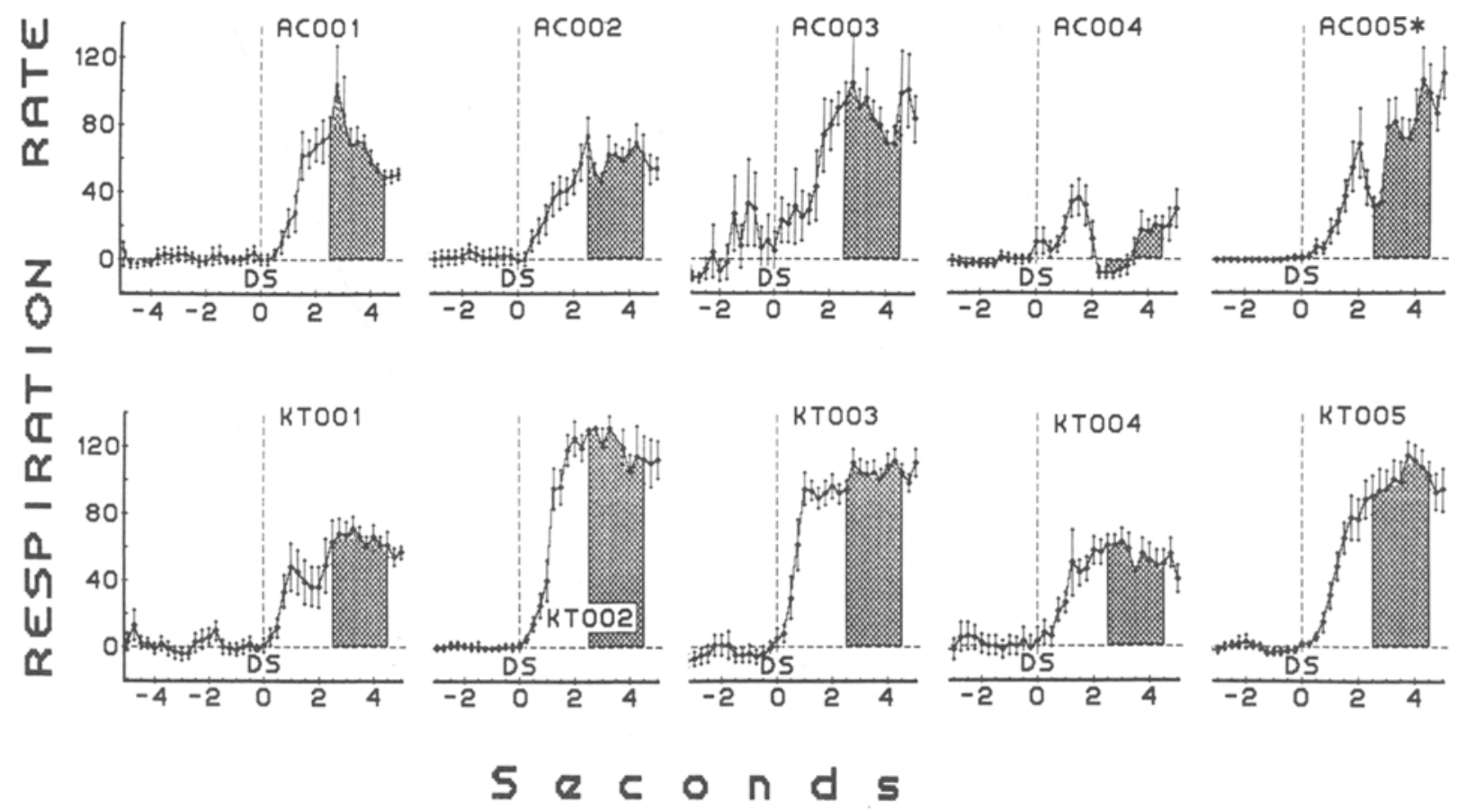

Figure 2. Respiration rate (cycles/min) for 5 sec preceding DS onset and 5 sec during DS presentation in individual adult (upper) and kitten (lower) subjects. *The ordinate was doubled for Subject ACOOS.
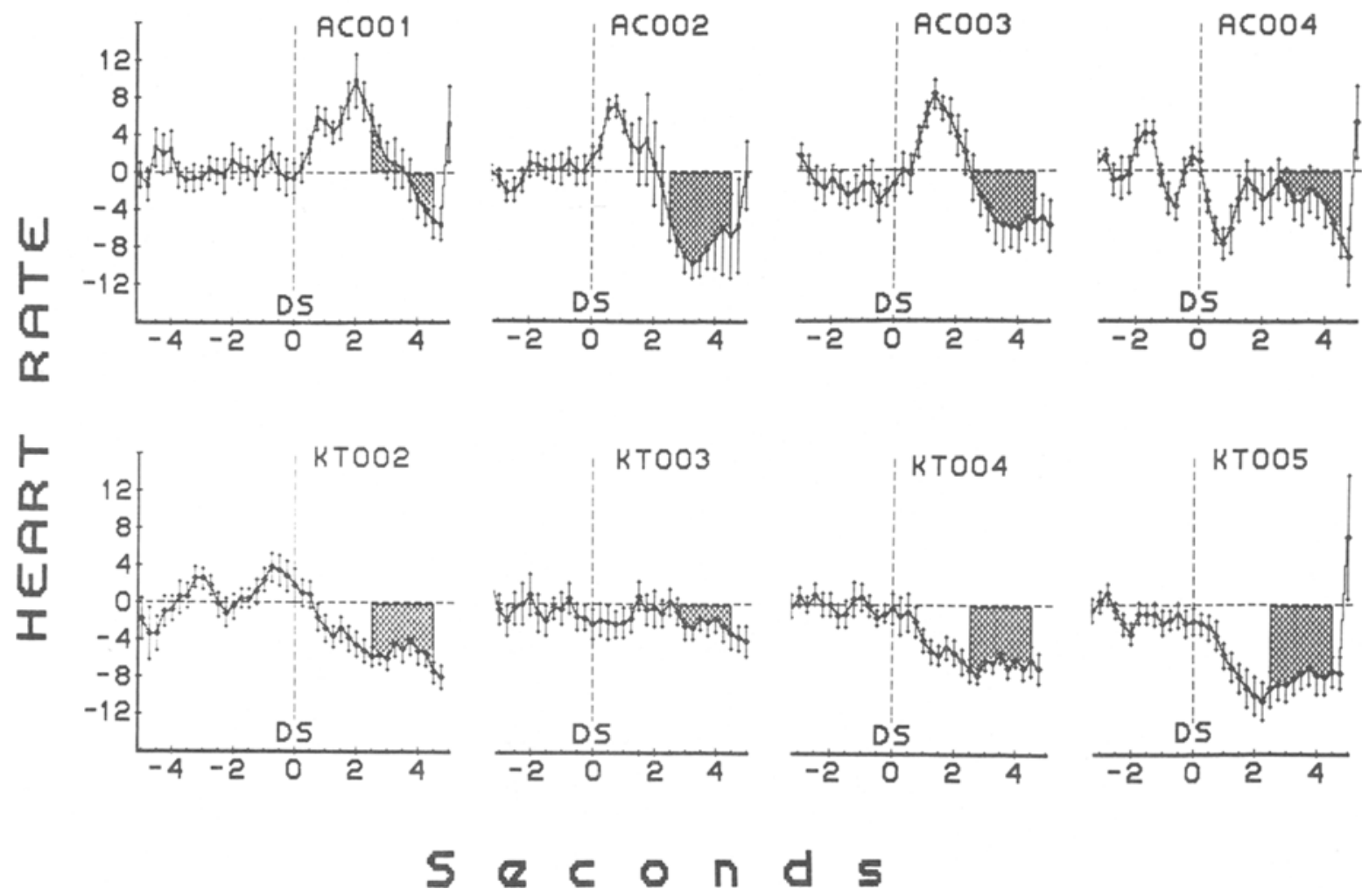

Figure 3. Heart rate as difference from baseline (beats/min) for 5 sec preceding DS onset and 5 sec during DS presentation in individual adult (upper) and kitten (lower) subjects. 
Table 1

Coefficients of Variation Across Trials[ $V=100(\mathrm{SD} / \mathrm{Mean}]$ for Individual Subjects

\begin{tabular}{|c|c|c|c|c|c|c|}
\hline \multirow[b]{2}{*}{ Subject } & \multicolumn{3}{|c|}{$\begin{array}{l}V=\text { SD Expressed as } \\
\text { Percent of the Mean }\end{array}$} & \multicolumn{3}{|c|}{$V$ Corrected for Slope } \\
\hline & $\begin{array}{l}\text { Respiratory } \\
\text { Amplitude }\end{array}$ & $\begin{array}{c}\text { Respiratory } \\
\text { Rate }\end{array}$ & $\begin{array}{l}\text { Heart } \\
\text { Rate }\end{array}$ & $\begin{array}{l}\text { Respiratory } \\
\text { Amplitude }\end{array}$ & $\begin{array}{c}\text { Respiratory } \\
\text { Rate }\end{array}$ & $\begin{array}{c}\text { Heart } \\
\text { Rate }\end{array}$ \\
\hline \multicolumn{7}{|c|}{ Adults } \\
\hline $\mathrm{AC} 001$ & 49 & 38 & 238 & 50 & 37 & 244 \\
\hline $\mathrm{ACOO2}$ & 22 & 40 & 170 & 23 & 38 & 177 \\
\hline $\mathrm{ACOO3}$ & 41 & 41 & 159 & 35 & 41 & 165 \\
\hline ACOO4 & 32 & 145 & 135 & 33 & 148 & 115 \\
\hline $\mathrm{ACOO5}$ & 13 & 39 & - & 13 & 34 & - \\
\hline \multicolumn{7}{|c|}{ Kittens } \\
\hline KT001 & 27 & 19 & - & 24 & 20 & - \\
\hline KT002 & 13 & 27 & 879 & 13 & 25 & 909 \\
\hline KT003 & 19 & 16 & 190 & 12 & 16 & 182 \\
\hline KT004 & 44 & 43 & 251 & 45 & 43 & 259 \\
\hline KT005 & 16 & 29 & 106 & 15 & 28 & 91 \\
\hline \multicolumn{7}{|c|}{ Overall Means } \\
\hline Mean & 28 & 34 & 266 & 26 & 43 & 268 \\
\hline$S D$ & 13 & 37 & 252 & 14 & 38 & 256 \\
\hline
\end{tabular}

Note $-V s$ are presented uncorrected (left panels) and corrected (right panels) for the slope of the intertrial regression line.

was no general skew in the heart-rate data. One animal out of 8 showed considerable skew over the 16 trials (AC002, 1.62); furthermore, even the largest departures from normality were not consistently signed. The absence of significant general skew in respiration-rate and heartrate measures is therefore not the result of consistently small departures from distributional normality of the measures, but of variability in skewness between subjects. An inspection of the distribution of respiration-rate and heart-rate responses across trials for individual subjects reveals skewness that varies in degree and direction be- tween subjects and, more ominously for tests of developmental and treatment effects, between age groups.

Correlations were calculated between each pair of dependent measures. Correlation coefficients are reported in Table 3. Small positive correlations were obtained for each combination of measures. Of the three sets of correlations, the two respiration measures were most highly correlated $(r=0.41)$; correlations between heart rate and each of the other two measures were slightly weaker (with respiration amplitude, $r=0.30$; with respiration rate, $r$ $=0.28$ ).

Table 2

Differences Between Mean (M) and Median (MD) and Coefificients of Skewness and Kurtosis Across 16 Trials for Individual Subjects

\begin{tabular}{|c|c|c|c|c|c|c|c|c|c|}
\hline \multirow[b]{2}{*}{ Subject } & \multicolumn{3}{|c|}{ Respiration Amplitude } & \multicolumn{3}{|c|}{ Respiration Rate } & \multicolumn{3}{|c|}{ Heart Rate } \\
\hline & $\mathbf{M}-\mathbf{M D}$ & SKEW & KURT & $\mathbf{M}-\mathbf{M D}$ & SKEW & KURT & $\mathbf{M}-\mathbf{M D}$ & SKEW & KURT \\
\hline \multicolumn{10}{|c|}{ Adults } \\
\hline $\begin{array}{l}\text { ACO01 } \\
\text { ACO02 } \\
\text { ACO03 } \\
\text { ACO04 } \\
\text { AC005 }\end{array}$ & $\begin{array}{r}1.87 \\
-5.23 \\
-19.61 \\
-6.97 \\
-0.29\end{array}$ & $\begin{array}{l}-0.43 \\
-0.72 \\
-0.55 \\
-0.87 \\
-0.89\end{array}$ & $\begin{array}{r}0.60 \\
-0.77 \\
-1.11 \\
-0.03 \\
1.48\end{array}$ & $\begin{array}{r}3.57 \\
-1.22 \\
3.90 \\
32.77 \\
-6.52\end{array}$ & $\begin{array}{r}0.91 \\
-0.10 \\
0.80 \\
0.57 \\
-0.29\end{array}$ & $\begin{array}{r}1.20 \\
-0.83 \\
-0.37 \\
-0.66 \\
-1.01\end{array}$ & $\begin{array}{r}-36.7 \\
31.14 \\
-22.03 \\
16.83 \\
-\end{array}$ & $\begin{array}{r}0.15 \\
1.62 \\
-0.84 \\
-0.46 \\
-\end{array}$ & $\begin{array}{r}-0.50 \\
2.36 \\
0.69 \\
-0.38 \\
-\end{array}$ \\
\hline \multicolumn{10}{|c|}{ Kittens } \\
\hline $\begin{array}{l}\text { KT001 } \\
\text { KT002 } \\
\text { KT003 } \\
\text { KT004 } \\
\text { KT005 }\end{array}$ & $\begin{array}{r}0 \\
-5.82 \\
2.65 \\
-13.90 \\
-4.09\end{array}$ & $\begin{array}{l}-0.40 \\
-0.82 \\
-0.41 \\
-1.04 \\
-1.07\end{array}$ & $\begin{array}{r}0.02 \\
0.09 \\
-1.02 \\
0.48 \\
1.16\end{array}$ & $\begin{array}{r}-2.40 \\
-9.81 \\
-0.84 \\
-9.13 \\
1.61\end{array}$ & $\begin{array}{l}-0.04 \\
-0.88 \\
-0.17 \\
-1.30 \\
-0.18\end{array}$ & $\begin{array}{r}-1.49 \\
-0.55 \\
-0.85 \\
1.88 \\
-0.85\end{array}$ & $\begin{array}{r}- \\
-26.58 \\
29.57 \\
7.39 \\
-17.46\end{array}$ & $\begin{array}{r}- \\
0.77 \\
0.10 \\
0.53 \\
-0.40\end{array}$ & $\begin{array}{r}-\overline{0.81} \\
-1.00 \\
-0.88 \\
-1.27\end{array}$ \\
\hline \multicolumn{10}{|c|}{ Overall Means } \\
\hline $\begin{array}{l}\text { Mean } \\
S D\end{array}$ & $\begin{array}{r}-5.14 \\
7.08 \\
\end{array}$ & $\begin{array}{r}-0.72 \\
0.26 \\
\end{array}$ & $\begin{array}{l}0.09 \\
0.88 \\
\end{array}$ & $\begin{array}{r}1.23 \\
12.11 \\
\end{array}$ & $\begin{array}{r}-0.14 \\
0.63 \\
\end{array}$ & $\begin{array}{r}-0.36 \\
1.05 \\
\end{array}$ & $\begin{array}{r}-2.23 \\
26.69 \\
\end{array}$ & $\begin{array}{l}0.18 \\
0.79\end{array}$ & $\begin{array}{r}-0.02 \\
1.22 \\
\end{array}$ \\
\hline
\end{tabular}


Table 3

Product-Moment Correlation Coefficients ( $r$ ) Between Pairs of Measures Across 16 Trials for Individual Subjects

\begin{tabular}{cccc}
\hline Subject & RA vs. RR & RA vs. HR & RR vs. HR \\
\hline \multicolumn{5}{c}{ Adults } \\
AC001 & 0.05 & 0.14 & 0.02 \\
AC002 & 0.48 & 0.38 & 0.75 \\
AC003 & 0.76 & 0.09 & 0.11 \\
AC004 & 0.27 & 0.28 & 0.32 \\
AC005 & 0.23 & - & - \\
& & Kittens & \\
KT001 & 0.23 & - & - \\
KT002 & 0.55 & 0.55 & 0.19 \\
KT003 & 0.70 & 0.35 & 0.28 \\
KT004 & 0.56 & 0.16 & 0.33 \\
KT005 & 0.23 & 0.45 & 0.26 \\
\hline
\end{tabular}

Note-Missing entries are due to incomplete heart-rate data for 2 subjects.

Respiration amplitude and rate and heart rate, sampled at 0.25 -sec intervals, are presented as group averages and standard errors in Figure 4. Observations were first averaged across the trials for each subject; group means and SEM were calculated from the set of subjects' mean scores ( $n=10$ for respiration and $n=8$ for heart rate). Analysis at the group level yields results generally similar to those obtained by analyzing individual subjects. Both respiration measures show a clear response pattern. Heart rate is obviously the most unstable measure between subjects. The pattern of heart-rate response varies between age groups: The insert in Figure 4 shows an early acceleratory component of the heart-rate response to the DS in adult cats that is absent in kittens. The coefficient of variability across subjects was $V=26.56$ for respiration amplitude, $V=42.49$ for respiration rate, and $V=48.30$ for heart rate, respectively.

\section{DISCUSSION}

The relative dearth of studies on the ontogeny of fear and failures to observe learning in young animals are undoubtedly due to the lack of a preparation that measures fear, is practical for use at early postnatal ages, and does not rely on specific motor or secretory reflexes, which may be functionally distinct in different age groups. Our present concern is to design a means of obtaining reliable, continuous, and easily quantified measurements of conditioned fear in cats. The procedure should (1) be applicable in subjects whose head is immobilized to permit recording from the brain or other CNS manipulations, (2) be applicable at various ages, permitting developmental studies of fear learning across age groups, and (3) yield robust and consistent data while allowing the subject to engage in locomotor behavior.

The data presented here are from a conditioning preparation recently developed in our laboratory. The critical dependent measure consisted of continuously monitored fluctuations in respiratory amplitude, particularly changes in respiratory amplitude elicited by conditioned aversive stimuli. Such danger signals elicited CRS responses simi- lar in magnitude and consistency to those observed in previous studies (Soltysik et al., 1984; Soltysik et al., 1983; Wilson \& Soltysik, 1985). CRS responses were also directly compared to concurrent respiration-rate and heartrate responses. Changes in respiration amplitude during the 5-sec danger signal were more consistent within and between subjects than changes in either respiration rate or heart rate. This conclusion was supported by an inspection of both individual-trials data (Figures 1-3) and group-averaged data (Figure 4). Furthermore, a comparison of individual and group data revealed that the representativeness of group averages varies between these three measures. The group-averaged respiration-amplitude response to the danger signal is representative of the form and magnitude of responding in virtually every subject;
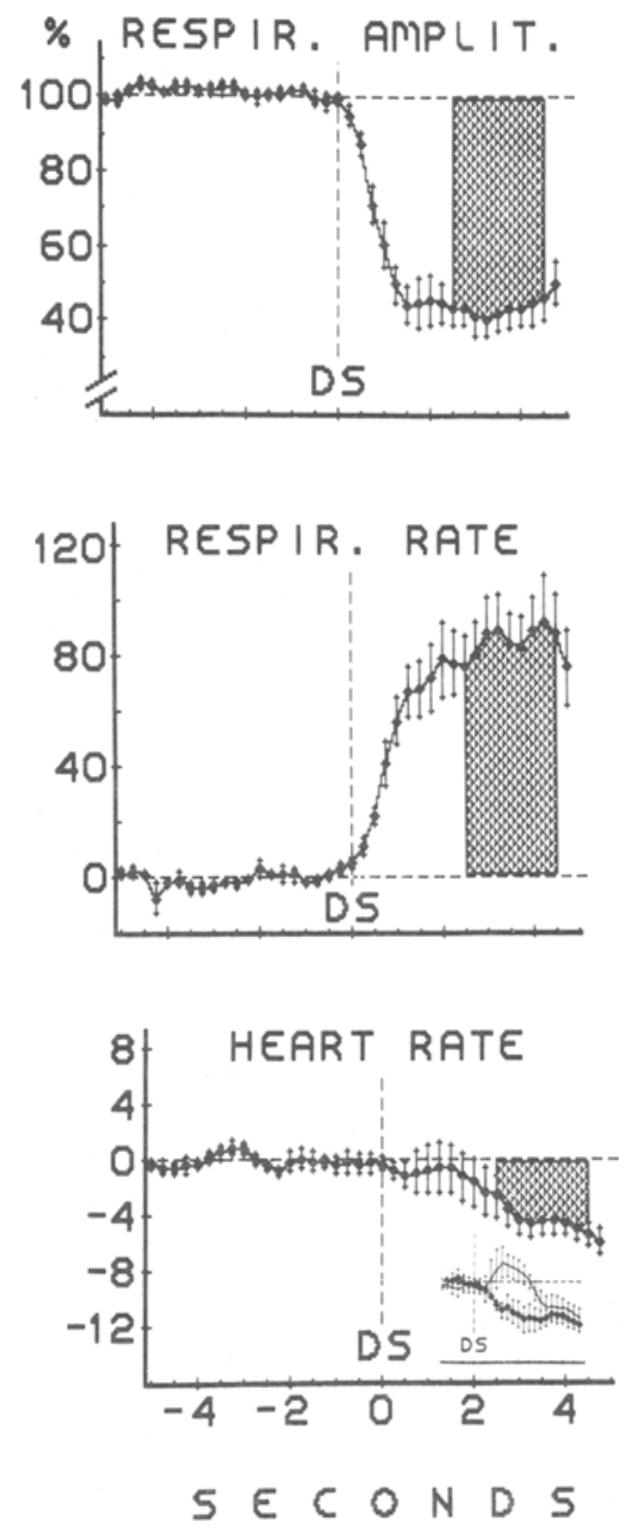

Figure 4. Overall mean respiration amplitude (upper), respiration rate (middle), and heart rate (lower) responses averaged first over each subject and then across subjects. 
the group-averaged respiration rate and heart rate are representative of fewer of the subjects' responses.

The pattern and distribution of respiration-amplitude suppression were more consistent across subjects than were changes in respiration rate. On the other hand, respiration amplitude and rate had similar intertrial coefficients of variation and, of the three pair-wise correlations, were most highly correlated. Thus, respiration rate might seem to be a reasonable measure of learning. Other data from our laboratory, however, suggest that similar changes in respiration rate (but not respiration amplitude) can be elicited by novel stimuli (unpublished observations), a CS- (Soltysik et al., 1984), and danger signals. Thus, changes in respiration rate, although fairly reliable, may not selectively reflect conditioned fear, as opposed to orienting to relatively novel or sudden stimuli.

The reliability of the CRS can be interpreted in two ways. First, it might reflect a phylogenetically old, fundamental associative process. The reliable occurrence and patterning of the CRS is consistent with ethologically based criteria for indices of fear-that is, that they appear quickly and are relatively invariant across trials, subjects, and groups (Bolles, 1970; Plotkin \& Odling-Smee, 1979). Alternatively, the reliability of the CRS measure might reflect insensitivity of the measure to important differences between animals, differences perhaps reflected in the relative heterogeneity of respiration-rate and heartrate responses. Our contention is that the CRS measure is extremely sensitive to the acquisition (Dess \& Soltysik, 1988) and extinction (Soltysik et al., 1984) of conditioned fear and conditioned inhibition of fear. The CRS is less sensitive to the idiosyncratic selection of motor strategies adopted in response to fear and their physiological concomitants. Such strategies can be expected to change according to the situation, prior experience, maturation, and species. Heart rate, for example, might reflect readiness for skeletal motor responses organized by fear, as well as anticipatory fear itself (Obrist et al., 1974). To the extent that animals differ in history, age, or ancestors, the pattern of heart rate during danger signals can be expected to vary. The difference in heart-rate patterns between kittens and adult cats in the present study might reflect such a difference in fear-motivated strategies, but not in the fear state per se. Thus, the choice of an index other than the CRS, such as heart rate, might be appropriate if determiners of diversity in conditioned and unconditioned motor responses are of interest.

The CRS paradigm offers procedural, theoretical, and statistical advantages over methods that rely on somatic motor responses as indices of fear, including the conditioned emotional response paradigm (CER) (Estes \& Skinner, 1941; Hunt \& Brady, 1951). Whereas the CER requires pretraining of a consummatory or operant baseline, animals require no training to breathe. The CRS is not dependent on the motor strategy adopted by the subjects: Cats that freeze and those that respond actively to danger signals show equally robust CRS responses (Soltysik et al., 1984).
The CRS procedure offers advantages over the CER in developmental studies. The CRS enhances comparability of baseline behaviors across age groups; it also eliminates the need for dietary restrictions, which may have undesirable effects on young subjects.

Relative to the CER, the CRS facilitates examination of the temporal dynamics of fear within trials and is not limited to rather long CS-US intervals. In addition, the CRS, unlike the CER, is not complicated by potential interactions between appetitive-baseline and fear-motivated behaviors. It also allows for the tracing of the instantaneous level of fear in microepochs of time, even in single trials; a number of trials must be averaged to achieve such resolution with the CER paradigm (Libby \& Church, 1975).

Statistical criticism leveled against the CER and its quantification by the suppression ratio focuses on its sensitivity to baseline changes that, in fact and in principle, can be dramatic, and also on the fact that the ratio is routinely 0 for most animals in at least some of the groups in an experiment. These features of CER data distort its distribution by imparting excessive skewness, which, in turn, can lead to spurious inflation of differences between groups (Hall, 1986; Hurwitz \& Davis, 1983). The CRS measure is also a ratio, as are many other indices of fear, and therefore does not eliminate these concerns. These concerns, however, are rendered less troublesome in the CRS preparation. There are physiological limits on baseline and conditioned changes in respiration amplitude: Maximal responses, even in well-trained animals, almost never reach 0 . And although our analysis has shown that the CRS measure also suffers from moderate skewness, the consistency of the skewness across subjects and groups lessens its interpretational impact relative to traditional assessment of the CER.

In conclusion, respiratory suppression observed in anticipation of noxious stimuli is a reliable phenomenon across trials, subjects, and age groups. It is somewhat less variable than respiration rate, and much less variable than the heart-rate changes that occur simultaneously. CRS is comparable in some respects to the conditioned suppression of appetitive behavior in the CER procedure; however, CRS exhibits fewer problems with the baseline level of the measure (no animal refuses to breathe), and exhibits only moderate skewness, which is consistent across subjects. Its independence from other indices of learning allows it to be used at early postnatal and preweaning ages. Its applicability for neurophysiological and pharmacological manipulations, in both adult and developmental studies, makes it at least a valuable addition-if not a preferable alternative - to the CER procedure in studies on associative learning in animals.

\section{REFERENCES}

Bolles, R. C. (1970). Species-specific defense reactions and avoidance learning. Psychological Review, 77, 32-48.

Dess, N. K., \& SoltysIK, S. S. (1988). Ontogeny of conditioned inhibition of conditioned respiratory suppression in kittens. Manuscript submitted for publication. 
ESTES, W. K., \& SKINNER, B. F. (1941). Some quantitative properties of anxiety. Joumal of Experimental Psychology, 29, 390-400.

GiBson, E. J. (1952). The role of shock in reinforcement. Journal of Comparative \& Physiological Psychology, 45, 18-30.

Hall, J. F. (1986). The conditioned emotional response as a model of Pavlovian conditioning. Pavlovian Journal of Biological Science, 21, 1-11.

HarRison, J., \& Buchwald, J. (1983). Eyeblink conditioning deficit in the old cat. Neurobiology of Aging, 4, 45-51.

Hunt, H. F., \& Brady, J. V. (1951). Some effects of electroconvulsive shock on a conditioned emotional response ("anxiety"). Journal of Comparative \& Physiological Psychology, 44, 88-98.

Hurwitz, H. M. B., \& DAvis, H. (1983). The description and analysis of conditioned suppression: A critique of the conventional suppression ratio. Animal Learning \& Behavior, 11, 383-390.

KIRK, R. E. (1968). Experimental design procedures for the behavioral sciences. Belmont, CA: Wadsworth.

LibBy, M. E., \& ChURCH, R. M. (1975). Fear gradients as a function of the temporal interval between signal and aversive event in the rat. Journal of Comparative \& Physiological Psychology, 88, 911-916.

Nicholas, T., Wolfe, G., Soltysik, S. S., Garcia, J. L., Wilson, W. J., AвRAнам, P. (1983). Postnatal development of heart rate patterns elicited by an aversive CS and US in cats. Pavlovian Journal of Biological Science, 18, 144-153.

Obrist, O. A., Howard, J. L., Lawler, J. E., Galosy, R. A., Meyers, K. A., Gaebelein, C. J. (1974). Cardiovascular function-Experimental studies. In P. A. Obrist, A. H. Black, J. Brener, \& L. V. DiCara (Eds.), Cardiovascular psychophysiology (pp. 136162). Chicago: Aldine.

Plotkin, H. C., OdLing-Smee, F. J. (1979). Learning, change and evolution: An inquiry into a teleonomy of learning. Advances in the Study of Behavior, 10, 1-41.

Reynierse, J. H., Scavio, M. J., Jr., \& Ulness, J. D. (1970). An ethological analysis of classically conditioned fear. In J. H. Reynierse (Ed.), Current issues in animal learning (pp. 33-54). Lincoln, NE: University of Nebraska Press.

SolTYSIK, S., \& KoNORSKI, J. (1966). Relations between classical and instrumental conditioning. XVIII International Congress of Psychol- ogy: Symposium 4. Classical and Instrumental Conditioning (pp. 6673). Moscow: Nauka.

SoltysiK, S. S., Nicholas, T., Wilson, W. J. (1984). Postnatal development of respiratory and vocal responses during aversive classical conditioning in cats. Pavlovian Journal of Biological Science, 19, 169-181.

SoltYsix, S., \& Wolfe, G. (1980). Protection from extinction by a conditioned inhibitor. Acta Neurobiologiae Experimentalis, 40, 291-311.

Soltysik, S. S., Wolfe, G., Garcia-Sanchez, J., \& Nicholas, T. (1982). Infantile and adult heart rate patterns in cats during aversive conditioning. Bulletin of the Psychonomic Society, 19, 51-54.

Soltysik, S. S., Wolfe, G. E., Nicholas, T., Wilson, W. J., \& GarCiA-SANCHEZ, J. L. (1983). Blocking of inhibitory conditioning within a serial conditioned stimulus-conditioned inhibitor compound: Maintenance of acquired behavior without an unconditioned stimulus. Learning \& Motivation, 14, 1-29.

Thompson, R. F. (1986). The neurobiology of learning and memory. Science, 233, 941-947.

Thompson, R. F., Donovan, N. H., Clark, G. A., Lavond, D. G., Lincoln, J. S., Madden, J. IV, Mamounas, L. A., Mauk, M. D., * McCormick, D. A. (1987). Neuronal substrates of discrete, defensive conditioned reflexes, conditioned fear states, and their interactions in the rabbit. In I. Gormezano, W. S. Prokasy, \& F. R. Thompson (Eds.), Classical conditioning (3rd ed., pp. 371-399). Hillsdale, NJ: Erlbaum.

WILsON, W. J., \& SolTysIK, S. S. (1985). The effects of pharmacological manipulations of nucleus accumbens on classically conditioned responses in cats. Acta Neurobiologiae Experimentalis, 45, 91-105.

WolFE, G. E., \& SoltYsIK, S. S. (1981). An apparatus for behavioral and physiological study of aversive conditioning in cats and kittens. Behavior Research Methods \& Instrumentation, 29, 637-642.

ZAR, J. H. (1974). Biostatistical analysis. Englewood Cliffs, NJ: Prentice-Hall.

(Manuscript received July 1, 1987; revision accepted for publication November 23, 1987.) 